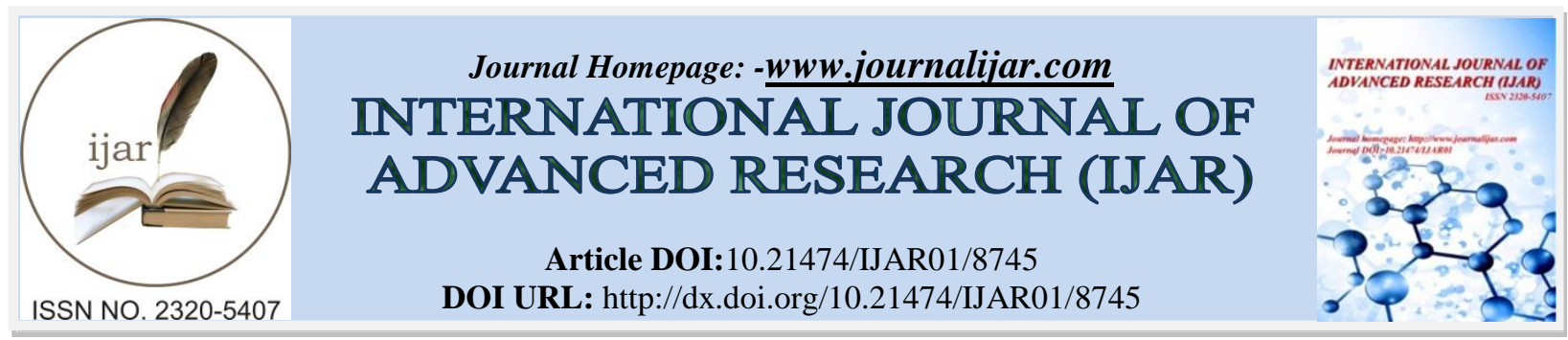

RESEARCH ARTICLE

\title{
ASSESS THE IMPACT OF STRUCTURED TEACHING PROGRAM ON KNOWLEDGE AND SKILL REGARDING PREVENTION OF MAJOR COMPLICATIONS OF IMMOBILITY IN ORTHOPAEDIC PATIENTS AMONG STAFF NURSES.
}

\author{
Kumari Sheetal ${ }^{1}$, Dilshada Wani ${ }^{2}$, Dar Nazir Ahmad ${ }^{3}$ and Singh Rajinder ${ }^{4}$. \\ 1. Senior staff nurse, smgsh, shalamar jammu, india. \\ 2. Vice principal \& hod mminc, skims soura srinagar, india. \\ 3. Statistical assistant pbcr radiation oncology skims soura srinagar india. \\ 4. Senior resident maharishi markandeshwar institute of medical science and research, ambala haryana.
}

\section{Manuscript Info}

\section{Manuscript History}

Received: 19 January 2019

Final Accepted: 21 February 2019

Published: March 2019

Key words:-

Structured teaching program, Knowledge, Skill, Complications, Immobility, Orthopaedic patients, Staff nurses.

\section{Abstract}

The present study was conducted to assess the impact of structured teaching program on knowledge and skill regarding prevention of major complications of immobility in orthopaedic patients among staff nurses at SKIMS Medical College and Hospital, Bemina Srinagar. The association between pre test knowledge and skill score of study subjects with demographic variables was also assessed. Quantitative research approach with one group pre test post test research design with purposive sampling technique to select study sample of 50 was used.Data was collected by using structured knowledge questionnaire and observational checklist. The result revealed that the structured teaching program was effective in improving the knowledge with the mean difference of $11.46(\mathrm{p}=0.03)$ and skill with the mean difference of $9.20(\mathrm{p}=0.001)$ at 0.05 level of significance. The result also revealed significant association between professional qualification and years of experience with pre test knowledge score and educational qualification with pre test skill score. Findings of the study concluded that structured teaching program was effective.

Copy Right, IJAR, 2019,. All rights reserved.

\section{Introduction:-}

Musculoskeletal system, the unique structure allows human beings to complete complex moments in their interaction with the environment. Activity restriction or inability to move freely refers to the term immobility. The word immobility or orthopaedic patients are closely related. Orthopaedic patients have impairment in mobility that results from prescribed restriction of movements. The effect of immobilization leads to many complications like pressure ulcers, deep vein thrombosis, constipation and other medical conditions like pulmonary infections, contracture etc. Musculoskeletal conditions are a major burden on individuals, health systems, and social care systems, with indirect costs being predominant. This burden has been recognized by the United Nations and World Health Organizations (WHO), by endorsing the Bone and Joint decade 2000- 2010.

The main purpose of the present study is to prevent complications arising out of immobilization by educating the staff nurses. As we know that nurses play an important role in the prevention of occurrence of major complications 
of immobility, as they are the one who early recognizes the signs and symptoms of disease condition during patient stay in hospital with immobility or fracture. For this purpose nurses should have adequate knowledge as inadequate knowledge is more hazardous than ignorance because the person who has inadequate knowledge may not be able to identify the deficiency properly, which inturn may lead to poor services resulting serious consequences. Similarly nurses with deficient knowledge may provide poor services in the care of immobilized orthopaedic patients and the outcome will be more complication rather than their prevention. For preventing the occurrence of these complications, nurses should have adequate and up to date knowledge to provide quality and cost effective care to the client. The researcher felt the need to explore the knowledge of the staff nurses dealing with orthopaedic condition in preventing selected complications of immobilization and to enhance their knowledge through structured teaching program that will help to improve the client's quality of life.

\section{Objectives of the study:}

1. To assess the pre - test knowledge score regarding prevention of major complications of immobility in orthopedic patients among staff nurses.

2. To assess the post - test knowledge score regarding prevention of major complications of immobility in orthopedic patients among staff nurses.

3. To evaluate the impact of structured teaching program on knowledge regarding prevention of major complications of immobility in orthopaedic patients among staff nurses by comparing mean pre test and mean post test knowledge scores

4. To assess the pre-test skillscore regarding prevention of major complications of immobility in orthopaedic patients among staff nurses.

5. To assess the post test skill score regarding prevention of major complications of immobility in orthopaedic patients among staff nurses.

6. To evaluate the impact of structured teaching program on skill regarding prevention of major complications of immobility in orthopaedic patients among staff nurses by comparing mean pre test and mean post test skill scores.

7. To associate the pre- test knowledge score of study subjects with their demographic variables (age, gender, professional qualification and years of experience).

8. To associate the pre- test skillscore of study subjects with their demographic variables (age, gender, professional qualification and years of experience).

\section{Hypotheses:}

1. $\mathbf{H}_{1}$ : There is significant increase in mean post-test knowledge score as compared to the mean pre test knowledge score on prevention of major complications of immobility in orthopaedic patients among staff nurses after the administration of structured teaching program at 0.05 level of significance.

2. $\mathbf{H}_{2}$ : There is significant increase in mean post-test skill score as compared to the mean pre test skill score regarding prevention of major complications of immobility in orthopaedic patients among staff nurses after the administration of structured teaching program at 0.05 level of significance.

3. $\mathbf{H}_{3}$ : There is significant association of pre test knowledge score on prevention of major complications of immobility in orthopaedic patients among staff nurses with their demographic variables (age, gender, professional qualification and years of experience) at 0.05 level of significance

4. $\quad \mathbf{H}_{4}$ : There is significant association of pre test skill score regarding prevention of major complications of immobility in orthopaedic patients among staff nurses with their demographic variables (age,gender, professional qualification and years of experience ) at 0.05 level of significance.

\section{Conceptual framework:}

The conceptual framework used is based on Imogen king's goal attainment theory (1960)

\section{Materials and methods:-}

Quantitative research approach with pre- experimental one group pre test post test design was used to assess the knowledge and skill of 50 staff nurses regarding prevention of major complications of immobility among orthopaedic patients at SKIMS Medical College and Hospital, Bemina Srinagar. Purposive sampling technique was used to collect data from study subjects and tool used for study was structured knowledge questionnaire and observational checklist.

The tool was divided into three sections:

Section 1: Demographic data (Age,Gender ,Professional qualification and Years of experience ) 
Section 2: Structured knowledge questionnaire (consisting of 64 items) regarding prevention of major complications of immobility among orthopaedic patients.

Section 3: observational checklist (consisting of 14 items) to assess skill level regarding use of Braden scale for assessing pressure ulcer.

The content validity of tool was ensured by submitting the tool to the experts in the field of medical surgical nursing, mental health nursing, nursing superintendent, professor and HOD of orthopaedic department etc. The reliability of the tool was determined by administering structured knowledge questionnaire and observational checklist to $5 \%$ of sample size. The two scores obtained at two different occasions were compared and calculated by using Karl Pearson's correlation reliability coefficient which was found to be " $r=0.94$ " Inter rater reliability of the checklist was computed and found to be " $\mathrm{r}=0.85$ " and the tool was found to be reliable.

A pilot study was conducted on $10 \%$ of total sample size. The mean pre interventional knowledge score was 39.40, median 38.00, standard deviation $\mathbf{5 . 3 6}$,range 14 The mean post interventional knowledge score was $\mathbf{5 8 . 8 0}$ median $\mathbf{5 9 . 0 0}$,Standard deviation 2.04, range $\mathbf{5}$. The mean difference between pre and post interventional knowledge score was 19.40 and $t$ value of $\mathbf{9 . 6 2}$ The mean pre interventional skill score was 5.60, median 6.00, SD 2.302. The post interventional skill score was 10.40, median 10, SD 1.140. The mean difference was 4.80 with a t value of 8.232 The study was found feasible and researchable.

\section{Results:-}

The data and the findings were entered in a master sheet followed by the analysis and interpretation using descriptive statistics (i.e. frequency, percentage, mean, median and standard deviation) and inferential statistics (i.e. t- test and ANOVA) according to the objectives of the study. The results obtained were presented in the following headings.

\section{Section I:}

Distribution of demographic variable of the study subjects

Table 1:-findings related to demographic variables $(n=50)$

\begin{tabular}{|l|l|l|l|}
\hline \multicolumn{2}{|c|}{ VARIABLES } & FREQUENCY & PERCENTAGE (\%) \\
\hline \multirow{4}{*}{ AGE } & $<30$ & 05 & 10 \\
\cline { 2 - 4 } & $30-40$ & 30 & 60 \\
\cline { 2 - 4 } & $41-50$ & 15 & 30 \\
\hline \multirow{4}{*}{ GENDER } & Male & 02 & 4 \\
\cline { 2 - 4 } & Female & 48 & 96 \\
\hline PROFESSIONAL & GNM & 23 & 46 \\
\cline { 2 - 4 } & B.Sc. Nursing & 25 & 50 \\
\cline { 2 - 4 } YEARS OF & M.Sc. Nursing & 02 & 4 \\
\cline { 2 - 4 } & $1-5$ & 6 & 12 \\
\cline { 2 - 4 } & $6-10$ & 13 & 26 \\
\cline { 2 - 4 } & $11-15$ & 4 & 8 \\
\cline { 2 - 4 } & $>15$ & 27 & 54 \\
\hline
\end{tabular}

Section II:

findings related to knowledge level

Table 2:-Pre test and post test knowledge score of study subjects regarding prevention of major complications of immobility in orthopaedic patients

\begin{tabular}{|l|l|l|l|l|}
\hline $\begin{array}{l}\text { Pre-test \& Post-test } \\
\text { knowledge score }\end{array}$ & No. of subjects in pre-test $(\mathrm{n}=50)$ & \multicolumn{2}{l|}{ No. of subjects in post-test $(\mathrm{n}=50)$} \\
\cline { 2 - 5 } & Frequency & Percentage & Frequency & Percentage \\
\hline poor (<16) & 10 & $20.0 \%$ & 0 & $0 \%$ \\
\hline Average (16-31) & $\mathbf{3 3}$ & $\mathbf{6 6 . 0 \%}$ & 0 & $0 \%$ \\
\hline Good (32-47) & 7 & $14.0 \%$ & 9 & $18.0 \%$ \\
\hline Excellent (48-64) & 0 & $0.0 \%$ & $\mathbf{4 1}$ & $\mathbf{8 2 \%}$ \\
\hline
\end{tabular}


Table 3:-Pre test and post test mean knowledge score, SD, median score, mode, range, minimum score, maximum score of study subjects regarding prevention of major complications of immobility in orthopaedic patients

\begin{tabular}{|l|l|l|l|l|l|l|l|l|}
\hline $\begin{array}{l}\text { Knowledge } \\
\text { score }\end{array}$ & Mean & Median & SD & Mode & Range & Max. & Min. & Mean $\%$ \\
\hline Pre test & 36.90 & 37.50 & 5.74 & 22 & 34 & 42 & 8 & $73.8 \%$ \\
\hline Post test & 48.39 & 42 & 3.30 & 48 & 27 & 62 & 35 & $96.78 \%$ \\
\hline
\end{tabular}

\section{To test the significance, following null hypothesis was formulated}

$\mathrm{H}_{01}$ : there is no significant increase in mean post test knowledge scores as compared to mean pre test knowledge score regarding prevention of major complications of immobility in orthopaedic patients among staff nurses at 0.05 level of significance

Table 4:-Comparison of mean pre test and mean post test knowledge score regarding prevention of major complications of immobility in orthopaedic patients

\begin{tabular}{|l|l|l|l|l|}
\hline $\begin{array}{l}\text { Pre test and post test } \\
\text { knowledge score }\end{array}$ & Mean \pm SD & Mean difference & t value & value \\
\hline Pre test score & $36.90 \pm 5.74$ & 11.49 & 9.067 & 0.003 \\
\cline { 1 - 2 } & $48.39 \pm 3.30$ & & & \\
\hline
\end{tabular}

The data in table 4 reveals that the mean difference between pre test mean score and post test mean score was 11.49 with t-value (9.067) which was found to be statistically significant $(\mathrm{p}=0.003)$ at $\mathrm{p}<0.05$ level of significance. This supports the research hypothesis $\left(\mathrm{H}_{1}\right)$ which states that there is significant increase in mean post-test knowledge score as compared to the mean pre test knowledge score at 0.05 level of significance. Hence null hypothesis $\left(\mathrm{H}_{01}\right)$ was rejected. This indicates that the structured teaching program was effective in improving the knowledge.

\section{Section III:}

Findings related to skill level

Table 5:-Pre test and post test skill score of study subjects regarding prevention of major complications of immobility in orthopaedic patients

\begin{tabular}{|l|l|l|l|l|}
\hline \multirow{2}{*}{ Pre test and post test skill score } & No. of subjects in pre test $(\mathrm{n}=50)$ & \multicolumn{2}{l|}{ No. of subjects in post test $(\mathrm{n}=50)$} \\
\cline { 2 - 5 } & Frequency & Percentage $(\%)$ & Frequency & Percentage $(\%)$ \\
\hline Poor $(<7)$ & 21 & 42 & 08 & 16 \\
\hline Good(7-14) & 29 & 58 & 42 & 84 \\
\hline
\end{tabular}

Table 6:-Pre test and post test mean skill score, SD, median score, maximum score, minimum score, range and mean percentage

\begin{tabular}{|l|l|l|l|l|l|l|l|}
\hline Skill score & Mean & Median & SD & Range & Min. & Max. & Mean \% \\
\hline Pre test & 6.80 & 7 & 1.841 & 8 & 3 & 11 & 13.6 \\
\hline Post test & 9.20 & 10 & 1.298 & 8 & 5 & 13 & 18.4 \\
\hline
\end{tabular}

To test the significance, following Null hypothesis was formulated.

$\mathrm{H}_{02}$ : There is no significant increase in mean post test skill scores as compared to mean pre test skill scores regarding prevention of major complications of immobility in orthopaedic patients among staff nurses after administration of structured teaching program at 0.05 level of significance.

Table 7:-comparison of pre test and post test skill score of study subjects regarding prevention of major complications of major complications of immobility in orthiopaedic patients

\begin{tabular}{|l|l|l|l|l|}
\hline $\begin{array}{l}\text { Pre test and post test } \\
\text { skill score }\end{array}$ & Mean \pm SD & Mean difference & t value & value \\
\cline { 1 - 2 } Pre test & $6.80 \pm 1.841$ & 2.4 & 11.67 & 0.001 \\
\hline Post test & $9.20 \pm 1.298$ & & & \\
\hline
\end{tabular}


The data in table 7 revealed that the mean difference between pretest and post test skill scores was found to be ( 2.4 ) at 0.05 level of significance with a p value of (0.001), which is statistically significant. Hence the null hypothesis $\mathrm{H}_{02}$ stating "There is no significant increase in mean post test skill scores as compared to mean pretest skill score regarding prevention of major complications of immobility in orthopaedic patients among staff nurses after administration of structured teaching program at 0.05 level of significance" was rejected and the research hyposthesis $\left(\mathrm{H}_{2}\right)$ was accepted .

\section{Section IV.}

Association of pre test knowledge and skill score with demographic variables

To find out the association, following Null hypothesis was formulated:

$\mathrm{H}_{03}$ : There is no significant association of pre-test knowledge score regarding prevention of major complications of immobility in orthopaedic patients among staff nurses with demographic variables ( Age , Gender, professional qualification and years of experience).

Table 8:-Association of pre test knowledge score with demographic variables

\begin{tabular}{|c|c|c|c|c|c|c|c|}
\hline Variables & Categories & $\begin{array}{l}\text { Good } \\
\text { knowledge }\end{array}$ & $\begin{array}{l}\text { Average } \\
\text { knowledge }\end{array}$ & $\begin{array}{l}\text { Poor } \\
\text { Knowledge }\end{array}$ & $\begin{array}{l}\text { Chi } \\
\text { Test }\end{array}$ & $\begin{array}{l}\mathbf{P} \\
\text { value }\end{array}$ & Result \\
\hline \multirow[t]{3}{*}{ AGE } & $<30$ & 1 & 2 & 1 & \multirow[t]{3}{*}{1.155} & \multirow[t]{3}{*}{0.965} & \multirow[t]{3}{*}{ NS } \\
\hline & $30-40$ & 14 & 32 & 1 & & & \\
\hline & $41-50$ & 1 & 3 & 0 & & & \\
\hline \multirow[t]{2}{*}{ GENDER } & MALE & 11 & 18 & 1 & \multirow[t]{2}{*}{0.598} & \multirow[t]{2}{*}{0.443} & \multirow[t]{2}{*}{ NS } \\
\hline & FEMALE & 4 & 11 & 0 & & & \\
\hline \multirow{3}{*}{$\begin{array}{l}\text { PROF. } \\
\text { QUALIFICATION }\end{array}$} & GNM & 4 & 18 & 1 & \multirow[t]{3}{*}{2.054} & \multirow[t]{3}{*}{0.011} & \multirow[t]{3}{*}{ S* } \\
\hline & BSC NSG. & 9 & 13 & 2 & & & \\
\hline & $\begin{array}{l}\text { MSC. } \\
\text { NSG. }\end{array}$ & 2 & 0 & 1 & & & \\
\hline \multirow{4}{*}{$\begin{array}{l}\text { YEARS OF } \\
\text { EXPERIENCE }\end{array}$} & $1-5$ & 2 & 3 & 0 & \multirow[t]{4}{*}{4.675} & \multirow[t]{4}{*}{0.004} & \multirow[t]{4}{*}{$\mathrm{S}^{*}$} \\
\hline & 6-10 & 3 & 11 & 1 & & & \\
\hline & 11-15 & 1 & 3 & 1 & & & \\
\hline & $>15$ & 02 & 14 & 09 & & & \\
\hline
\end{tabular}

*= Significant: $\quad$ NS = Not significant

The data presented in the table 8 indicates that there was statistically significant association between pre-test knowledge with professional qualification $(\mathrm{p}<0.011)$ and years of experience $(\mathrm{p}<0.004)$.

The above findings support the research hypothesis $\left(\mathrm{H}_{3}\right)$ which states that there is a significant association of pre test knowledge of staff nurses with the professional qualification and years of experience and hence the null hypothesis was rejected for this variable, which states that "there is no significant association of pre test knowledge with demographic variable."

While as no association of pre test knowledge was found between other two variables (Age and gender ) and hence null hypothesis was accepted for these two variables $\left(\mathrm{H}_{03}\right)$ which states that there is no significant association of pre test knowledge with demographic variables .

To find out the association, following Null hypothesis was formulated:

$\mathrm{H}_{04}$ : There is no significant association of pre-test skill scores of staff nurses regarding prevention of major complications of immobility in orthopaedic patients with demographic variables (age, gender, professional qualification and years of experience).

Table 9:-Association of pre test skill score with demographic variables

\begin{tabular}{|l|l|l|l|l|l|l|}
\hline Variables & Categories & Good skill & Poor skill & Chi test & p value & Result \\
\hline
\end{tabular}




\begin{tabular}{|c|c|c|c|c|c|c|}
\hline \multirow[t]{3}{*}{ Age } & $<30$ & 0 & 8 & \multirow[t]{3}{*}{1.115} & \multirow[t]{3}{*}{0.573} & \multirow[t]{3}{*}{ NS } \\
\hline & $30-40$ & 3 & 24 & & & \\
\hline & $41-50$ & 2 & 13 & & & \\
\hline \multirow[t]{2}{*}{ Gender } & Male & 0 & 2 & \multirow[t]{2}{*}{1.452} & \multirow[t]{2}{*}{0.431} & \multirow[t]{2}{*}{ NS } \\
\hline & Female & 15 & 33 & & & \\
\hline \multirow{3}{*}{$\begin{array}{l}\text { Professional } \\
\text { qualification }\end{array}$} & GNM & 3 & 19 & \multirow[t]{3}{*}{10.646} & \multirow[t]{3}{*}{0.043} & \multirow[t]{3}{*}{$\mathrm{S}^{*}$} \\
\hline & B.Sc. $(\mathrm{N})$ & 4 & 18 & & & \\
\hline & M.Sc. (N) & 3 & 2 & & & \\
\hline \multirow{4}{*}{$\begin{array}{l}\text { Years of } \\
\text { experience }\end{array}$} & $1-5$ & 1 & 4 & \multirow[t]{4}{*}{2.128} & \multirow[t]{4}{*}{0.637} & \multirow[t]{4}{*}{ NS } \\
\hline & $6-10$ & 4 & 9 & & & \\
\hline & $11-15$ & 0 & 4 & & & \\
\hline & $>15$ & 8 & 20 & & & \\
\hline
\end{tabular}

$\mathrm{S}^{*}$ :Only professional education shows the significance association $(\mathrm{p}<0.05)$

The data presented in the table 9 indicates that there was statistically significant association between pre-test skill scores of subjects with their professional qualification $(\mathrm{p}=0.043)$, while as no association was found with other demographic variables such as age, gender and years of experience of study subjects

Hence, the researcher accepted the research hypothesis $\left(\mathrm{H}_{4}\right)$ which states that " there is signification association of pre test skillscore with demographic variables " and rejected the null hypothesis $\left(\mathrm{H}_{04}\right)$ which states that there is no significant association of pre-test knowledge scores of staff nurses regarding prevention of major complications of immobility in orthopaedic patients with selected demographic variables (age, Gender and years of experience )

\section{Discussion:-}

Most of the subjects i.e, $30(60 \%)$ were in the age group of 30- 40 years, about $15(24 \%)$ were in the age group of $41-50$ and $5(10 \%)$ were in the age group of $<30$ years. These findings are comparable to the findings of a study conducted by Manju John ${ }^{46}(\mathrm{n}=50)$ to compare the knowledge about prevention of pressure ulcer among nurses working in selected hospitals, in district Drug (C.G) . The study revealed that majority of the subjects 37 (74\%) belonged to the age group of above 35 years, while 12(24\%) belonged to the age of $31-35$ and minority $1(2 \%)$ belonged to the age group of 21- 25 years.

In the present study, the distribution of male subjects were $2(4 \%)$ males and female subjects $48(96 \%)$ in the study sample. This finding is comparable to the findings of the study byAbin M Antony, K.T Moly and Dhanya ${ }^{22}$ $(\mathrm{n}=100)$ conducted on assessment of knowledge and self reported clinical practice on prevention of Deep Vein Thrombosis (DVT) among staff nurses, where there were 90 (90\%) females and 10 (10\%) males and another study was conducted by Hossein Rafiei, Mohammad Asmaeli Adbar and Ali Hassanpoor Dehkordi ${ }^{50}(\mathrm{n}=185)$ regarding knowledge about pressure ulcer prevention , classification and management: a survey of registered nurses working with trauma patients in the emergency department where there were $128(80.5 \%)$ females and $13(19.5 \%)$ males.

Regarding the professional qualification, maximum number of the study subjects i.e, 25(50\%) were having B. Sc. Nursing, about 23(46\%) were having GNM as professional qualification and 2 (4\%) of subjects were M. Sc. In nursing These findings are comparable to the findings of study by Neelam Sawanr and Mahadeo Shinde ${ }^{49}(\mathrm{n}=193)$ on nurses knowledge and practice towards prevention of pressure ulcer in Tertiary care hospital , where majority $123(63.7 \%)$ of the study subjects were educated up to GNM while $43(22.3 \%)$ subjects were educated upto BSC Nursing, 16(8.3\%) subjects with were educated up to ANM and 11(5.7\%) were educated up to PBBSC

Regarding the years of experience, majority of study subjects $27(54 \%)$ had $>15$ years of experience, 13(26\%) of study samples had 6- 10 years of experience, 6(12\%) of study subjects had 1- 5 years of experience and $4(8 \%)$ of study samples had 11- 15 years of experience These findings are comparable to the findings of study by Neelam Sawanr and Mahadeo Shinde ${ }^{49}(\mathrm{n}=193)$ on nurses knowledge and practice towards prevention of pressure ulcer in Tertiary care hospital , where most of $162(83.9 \%)$ study subjects had 1- 5 years of experience , $8(4.1 \%)$ study subjects had 6- 10 years of experience , 3( 1.6\%) study subjects had 11- 15 years of experience, 3(1.6\%) study subjects had 16- 20 years of experience and 17(8.8\%) study subjects had above 20 years of experience.

The pre-test (Mean $\pm \mathrm{SD}$ ) knowledge scores of the subjects was (36.90 \pm 5.74$)$.In the pre-test, most of the subjects 33 (66\%) had average knowledge level, 10(20\%) had poor knowledge level and 7(14\%) had good knowledge level. 
These findings revealed that majority of the subjects had average knowledge level regarding prevention of major complications of immobility in orthopaedic patients.

These findings are consistent with the findings of a study conducted byAbin M Antony, K T Moly and Dhanya R Dharan $^{22}$ on assessment of knowledge and self reported clinical practice on prevention of deep vein thrombosis (DVT) among staff nurses. The study results shows that majority of the subjects 58(58\%) had average knowledge and $42(42 \%)$ had poor knowledge on prevention of deep vein thrombosis. This implies that the staff nurses had lack of knowledge regarding prevention of major complications of immobility in orthopaedic patients.

The post-test knowledge scores reveal that majority of the study subjects $41(82 \%)$ had excellent knowledge, and 9(18\%) had good level of knowledge and none of the subjects had average and poor knowledge in the post-test. The post-test (Mean $\pm \mathrm{SD}$ ) knowledge score was $(48.39 \pm 3.30)$. These findings reveal the subjects had developed excellent knowledge level in the post-test among staff nurses regarding prevention of major complications of immobility in orthopaedic patients.

The findings are consistent with the study conducted bySasmita Das, Anjali Sahoo and Rasmita Swain ${ }^{62}$ on effectiveness of the planned teaching program on deep vein thrombosis among the staff nurses of selected hospital Bhubneshwar. The mean pre test score of knowledge of staff nurses was 24.6 and after planned teaching program it was 77.3 which denotes that there was some increase in knowledge score after planned teaching program

The post test (Mean $\pm \mathrm{SD}$ ) knowledge score of the study subjects was $(48.39 \pm 3.30)$ which is significantly higher than the mean pre test knowledge $(36.90 \pm 5.74)$ score of study subjects with mean difference of (11.49). The mean difference was statistically significant $(\mathrm{p}=0.000)$. This indicates that the 'Structured teaching program' was effective in increasing the knowledge score of staff nurses regarding prevention of major complications of immobility in orthopaedic patients.

The findings are supported by the findings of the study conducted by Kour Ravneet, Saagi Manjeet Kour and Choudhary Rashmi ${ }^{59}$ to evaluate the effectiveness of structured teaching program on knowledge regarding prevention and management of deep vein thrombosis in patients among nursing staff. The results revealed that the mean pre test knowledge score of control group was 15 and in experimental group it was 13.8 whereas mean post test knowledge score control group was 14 and 20.2 in experimental group. The difference between mean pre test and mean post was statistically significant at $\mathrm{p}<0.05$

The findings are also supported by the findings of the study conducted by Sasmita Das, Anjali Sahoo and Rasmita Swain $^{62}$ on effectiveness of the planned teaching program on deep vein thrombosis among the staff nurses of selected hospital Bhubneshwar . the mean pre test score of knowledge of staff nurses was 24.6 and after planned teaching program it was 77.3 which denotes that there was some increase in knowledge score after planned teaching program Hence, it is evident that post-test knowledge scores of study subjects were higher than the pre-test knowledge scores.

The pre-test (Mean \pm SD) skill scores of the subjects was $(6.80 \pm 1.841)$.In the pre-test, most of the subjects 21 (42\%) had poor skill and 29(58\%) had good skill These findings revealed that majority of the subjects had good skill regarding use of Braden scale for assessing pressure ulcers. Supportive studies were not found.

The post-test skill scores reveal that most of the study subjects $42(84 \%)$ had good skill and $08(16 \%)$ of the subjects had poor skill in the post-test. The post-test $($ Mean \pm SD) skill score was $(9.20 \pm 1.298)$. These findings reveal the subjects had developed good skill in the post-test and there is a higher post-test skill score.Supportive studies were not found

The post test (Mean $\pm \mathrm{SD})$ knowledge score of the study subjects was $(6.80 \pm 1.841)$ which is significantly higher than the mean pre test knowledge (9.20 \pm 1.298$)$ score of study subjects with mean difference of (2.4).The mean difference was statistically significant $(\mathrm{p}=0.000 *)$. This indicates that the demonstration was effective in increasing the skill score of staff nurses regarding use of Braden scale for assessing pressure ulcers.Supportive studies were not found.

Findings of the present study revealed that there was statistically significant association of the pre-test knowledge scores with the professional qualification and years of experience of the study subjects $(\mathrm{p}=0.011)$ and $(\mathrm{p}=0.004)$ 
while as no association was found between the pre-test knowledge scores of the study subjects with other demographic variables like age $(\mathrm{p}=0.965)$, and gender $(\mathrm{p}=0.443)$ at 0.05 level of significance.

These findings are consistent with the findings of a study conducted by Nurhusein Nuru, Fisseha Zewdu, Senafikish Amsalu and Yohannes Mehretie ${ }^{47}$ on knowledge and practice of nurses towards prevention of pressure ulcer and associated factors in Gondar university, Northwest Ethiopia. The study concluded that having higher educational status, attending formal training and being experienced were positively associated with knowledge

Findings of the present study revealed that there was statistically significant association of the pre-test skill scores with the professional qualification of the study subjects $(\mathrm{p}=0.043)$, while as no association was found between the pre-test skill scores of the study subjects with other demographic variables like age $(\mathrm{p}=0.573)$, gender $(\mathrm{p}=0.431)$, and years of experience $(\mathrm{p}=0.637)$ at 0.05 level of significance. No supportive studies were found.

\section{Conclusion:-}

The following conclusions were drawn on the basis of the findings of the study: The staff nurses were having average level of knowledge in pre test regarding prevention of major complications of immobility in orthopaedic patients and thus there is a need for educating the staff nurses. The mean post test knowledge and skill scores increased after administration of structured teaching program indicating that structured teaching program was effective in improving knowledge and skill of staff nurses. Except for professional qualification and years of experience there was no significant association of pre test knowledge score with other demographic variables ( age and gender ) was found whereas in pre test skill association was found only with single variable i.e. professional qualification except others like Age, Gender and Years of experience. Therefore, it was concluded that structured teaching program was effective in improving the knowledge and skill of staff nurses regarding prevention of major complications of immobility in orthopaedic patients.

\section{Biblioraphy:-}

1. Potter AP, Ann GP. Fundamentals of nursing. $5^{\text {th }}$ ed. Missiouri : mosky publishers; 2006, p -236-245

2. Lewis, heitkemper, Dirksen, o' brien, bucher. Medical surgical nursing : assessment and management of clinical problems. $7^{\text {th }}$ ed. Delhi; Elsevier publication; 2009. P.- 1522- 42

3. Frances Donovan manathan, Marianne neighbours, Judith K sande, jane F. marek, carol J green. Phipp's medical surgical nursing: health and illness prospective. $8^{\text {th }}$ ed. India: Elsevier publishers; 2009. P.- 1522- 42

4. Pande PK. Outline of sports medicine. $1^{\text {st }}$ ed. New delhi. Jaypee brothers publishers; 2000. P.- 137

5. Black M. joyce, Jane Hokanson Hawks. Medical- Surgical Nursing clinical management for positive outcomes. $7^{\text {th }}$ ed. Vol. 1. Elsevier publications:St. Lousi;2005.p-2023-2050

6. DT ramely,T jaeblon. Pressure ulcer in orthopaedics. J Am Acad. Orthop surg. 2010; vol.18(9):p-568-75

7. Ali M. Al.- shaded. Prevalence of pressure ulcer in orthopaedic patients. The Iraqi postgraduate medical journal. 2012; vol. 11(4): p.- 529- 535

8. Suzanne CS, Brenda GB. Textbook of medical surgical nursing. $10^{\text {th }}$ edition. philadelphia: lippincott wilkin publishers; 2004. P.- 142- 5

9. Kakar AK and smith rustom SK. Incidence of venous thromboembolism in orthopaedic surgery . thromboembolism $n$ orthopaedic surgery. 2013:p. 11- 17 .doi:10.1007/978-1-4471-4336-9-2

10. Makhdom M. asim , cota adam, ruth chaytor. Incidence of symptomatic deep venous thrombosis after Achilles tendon rupture. The journal of foot and ankle surgery. 2013; vol. 52(5): p. - 584- 587Retrieved from: https://www.researchgate.net/publication/236458828 